\title{
Perspectives of fishers on turtle bycatch and conservation strategies in a small-scale inland commercial fyke net fishery
}

\author{
Vivian M. Nguyen ${ }^{1, *}$, Sarah M. Larocque ${ }^{1,2}$, Lauren J. Stoot ${ }^{1,2}$, Nicholas A. Cairns ${ }^{1,2}$, \\ Gabriel Blouin-Demers ${ }^{2}$, Steven J. Cooke ${ }^{1}$
}

${ }^{1}$ Fish Ecology and Conservation Physiology Laboratory, Department of Biology, Carleton University, 1125 Colonel By Dr., Ottawa ON K1S 5B6, Canada

${ }^{2}$ Herpetology Laboratory, Department of Biology, University of Ottawa, 30 Marie Curie, Ottawa ON K1N 6N5, Canada

\begin{abstract}
We compiled information on the perspectives of fishers on turtle bycatch, turtle conservation, and turtle bycatch reduction strategies (BRSs). Our research efforts focused on a smallscale inland fyke net commercial fishery in Ontario, Canada, where turtle bycatch has been identified as a potential conservation concern. We conducted 18 complete and 3 partial telephone interviews with fishers ( $41 \%$ participation rate). Rates of turtle encounters varied between fishing behaviours (e.g. preferred depth of sets, habitat), and between water bodies, regions, and fishing seasons, resulting in varying perspectives with respect to turtle bycatch. There was a general lack of understanding as to the reasons why turtles are protected. None of the respondents recognized turtle bycatch as a conservation issue. They felt that threats to turtle populations were external to the fishery, resulting in negative feedback regarding various BRSs. Other barriers to adopting BRSs were costs (e.g. of reduced fishing opportunities, changes to gear, time and effort) and apprehension of potential changes to the fishery. Few fishers would voluntarily modify their gear; therefore, incentives (e.g. compensation, increased quota) may be needed to convince fishers to adopt mitigation strategies. Some fishers had already adopted their own BRS for turtles (e.g. moving nets upon encounter of turtles, using air spaces to improve turtle survival). Therefore, sharing fisher-driven, grass roots success stories with other fishers could promote support for changes in fishing practices. Greater awareness about the impacts of turtle mortalities may help build understanding and support for turtle conservation initiatives.
\end{abstract}

KEY WORDS: Turtle bycatch - Social science - Commercial fishing - Telephone interviews · Attitudes of fishers $\cdot$ Species at risk $\cdot$ Human dimension $\cdot$ Risk perception

Resale or republication not permitted without written consent of the publisher

\section{INTRODUCTION}

Bycatch is a pressing conservation problem around the globe in both marine (Lewison et al. 2004) and freshwater (Raby et al. 2011) systems. Recently, there has been a growing recognition that understanding conservation social science (Mascia et al. 2003) and associated knowledge of the human dimensions (HD; Ditton 2004) of bycatch and bycatch reduction is key to achieving meaningful conservation advances (re- viewed in Campbell \& Cornwell 2008) such as the design and implementation of bycatch reduction strategies (BRSs). For example, the perspective of fishers could help identify barriers to the adoption of various BRSs (Campbell \& Cornwell 2008, Lewison et al. 2011). In some cases, fishers may be unconvinced that there is a 'bycatch problem' or simply do not understand the problem, so HD research is useful in identifying their perceptions of threats. Understanding perceptions can ultimately help convince fishers 
to participate in BRS design and implementation (e.g. Tucker et al. 1997). Since fishers are familiar with both the problem and the fishing gears, HD studies provide them with an opportunity to contribute new and practical information, to refine existing strategies, or to explore alternative strategies (Campbell \& Cornwell 2008). Indeed, this bottom-up approach to BRS development is believed to create better technical solutions (Campbell \& Cornwell 2008), to generate trust between fishers, scientists, and management agencies (Kennelly \& Broadhurst 1996, Kennelly 1999, Hall \& Mainprize 2005), and to increase acceptance and compliance by empowering fishers and developing a sense of resource stewardship (Kennelly 1999, Kennelly \& Broadhurst 1996, Gilman et al. 2006a,b). Finally, because fisher adoption of BRSs is typically associated with an active outreach and education program (Tucker et al. 1997, Kennelly 1999, Broadhurst 2000, Cox et al. 2007), HD studies can also be useful in identifying relevant content as well as the best means for dissemination of knowledge which will presumably facilitate acceptance (Tucker et al. 1997, Broadhurst 2000, Cox et al. 2007, Watson 2007). Overall there are relatively few studies of the social aspects of bycatch. To our knowledge all such work has been focused on marine fisheries, and most has been obtained anecdotally (Piovano et al. 2012) rather than through structured HD surveys (reviewed in Campbell \& Cornwell 2008, but see Moore et al. 2010, Carruthers \& Neis 2011).

Small-scale inland commercial fisheries often employ passive gears such as fyke nets, trap nets and gill nets to capture targeted fish. In eastern Ontario, fyke nets are passively fished (often left for long durations) and can catch any mobile species that inhabit the area and are large enough to be retained by the mesh (Hubert 1996; see Fig. 1 in Larocque et al. 2012a). Fishing has occurred in this region with limited to no regulation for up to $200 \mathrm{yr}$ (Ontario Ministry of Natural Resources [OMNR] pers. comm.). Commercial licenses date as far back as 1961, and by 1965 the modern fishery was created. Today, the fishery targets pan fish such as sunfish Lepomis spp., bullheads Ameiurus spp., yellow perch Perca flavescens, rock bass Ambloplites ruperstris, and black crappie Pomoxis nigramaculatus Burns, 2007. Passive fishing gears have low species selectivity, and bycatch (including game fish) in fyke nets (and other passive nets) has been documented in this fishery (Larocque et al. 2012a, see Figs. 1 \& 2 in Larocque et al. 2012c), as well as in other inland fisheries around the globe (Barko et al. 2004, Lowry et al. 2005). The incidental capture of adult freshwater turtles, includ- ing species at risk (Larocque et al. 2012a), is a recurring issue in Ontario and elsewhere: turtles can drown if not provided with access to air. Freshwater turtle bycatch mortalities have been documented to range from $\sim 10$ to $100 \%$ while held in trap nets for 24 to $72 \mathrm{~h}$ (Bishop 1983, Barko et al. 2004, Fratto et al. 2008), with increased mortality associated with longer net sets and higher water temperature (Fratto et al. 2008). To our knowledge there is no mention of turtles as bycatch species until 1988 when 'turtle' was added to licenses as a group not to be kept for sale (OMNR pers. comm.). Prior to 1988, it is assumed that all turtle species were collected and sold.

In Ontario, 7 of 8 turtle species are at risk according to the Committee on the Status of Endangered Wildlife in Canada (COSEWIC 2013). The commercial fyke net fishery in eastern Ontario frequently encounters painted turtles Chrysemys picta that are not at risk, but also snapping turtles Chelydra serpentina, northern map turtles Graptemys geographica, and eastern musk turtles Sternotherus odoratus that are listed as 'special concern' (species that may become endangered if nothing is done to reverse factors leading to extinction or extirpation). Additionally, the fishery also interacts less frequently with Blanding's turtles Emydoidea blandingii and spiny softshell turtles Apalone spinifera which are 'threatened' (likely to become endangered if nothing is done to reverse factors leading to extirpation or extinction) (Carrière 2007, Larocque et al. 2012a). The magnitude of the impacts of bycatch mortality on turtle populations is currently unknown; however, long-lived organisms with late maturation and naturally low recruitment, such as turtles, can experience significant impacts to the population from slight additional adult mortality.

To minimize the number of bycatch mortalities, the regulating body, the OMNR, typically implements seasonal and temporal closures. Additionally, mandatory net tending was implemented in 2011 with varying frequencies according to the season and temperature, ranging from every $2 \mathrm{~d}$ (during warmer temperatures) to once every $14 \mathrm{~d}$ (during cooler temperatures) (OMNR pers. comm.) Frequent net checks can help prevent turtle bycatch mortality (Larocque et al. 2012a); however, Larocque et al. (2012a) documented high activity and capture of turtles in the spring (typically early April until closure) in an eastern Ontario Lake, suggesting that turtle capture can still potentially be high during the fishing season and that other bycatch reduction strategies such as gear modifications may be used to reduce bycatch mortality. Research efforts in eastern Ontario focused ini- 
tially on documenting the scope of the problem and have recently transitioned to exploring changes to fishing practices (e.g. seasonal closures, tending frequency guidelines) and to fishing gear (i.e. turtle excluders or escape devices; Larocque et al. 2012b). To date, these research efforts have been conducted rather independently of the commercial fishers, and there is concern that potential BRSs known by the fishers have not been considered, or that barriers may exist to the adoption (voluntary or mandated) of various bycatch reduction devices (BRDs) even if they are shown to be effective.

The objective of our study was to compile information on the perspectives of fishers on turtle bycatch, turtle conservation, and the use and implementation of various BRSs to inform resource management and conservation. Our sample frame was all licensed and active commercial fishers in eastern Ontario that use fyke nets in littoral areas to target pan fish. We used mixed methods (i.e. qualitative and quantitative), semi-structured telephone interviews. The actual number of licensed fishers is relatively small, which allowed us to survey a large proportion of the community of relevant fishers and ensure that our conclusions were applicable to the entire fishery. The general insights and perspectives should also be of interest to the broader conservation science community.

\section{METHODS}

\section{Interview}

Telephone interviews with both closed- and openended questions were conducted in a semi-structured format, which allowed participants to offer unsolicited views and opinions. We interviewed active commercial fishers that use passive live capture methods (i.e. fyke, hoop, and trap nets - herein called fyke nets) targeting pan fish and coarse fish in eastern Ontario, Canada. Due to the varied geographic locations of fishers and their unpredictable schedules, telephone interviews were the best method of contact that provided opportunities to gather in-depth information and explore bycatch issues.

Our interviews consisted of 6 short sections: (1) 'fishing background and effort', consisting of questions related to fisher experience, target species, fishing gear (type and quantity), fishing location, fishing seasons, and importance of fishing; (2) 'characterizing fishing practices and frequency of turtle encounter'; (3) 'fisher awareness, and perspective on turtle bycatch and turtle conservation', which consisted of questions related to turtle conservation, perceived threat(s) to turtles, and perception of turtle bycatch (what affects survival, long-term effects of fishery capture); (4) 'suggestions to reduce turtle bycatch', which consisted of questions on how to prevent bycatch of turtles, how to ensure survival of turtles inside a net, and reactions towards gear modifications versus time/area restrictions; (5) 'use and implementation of BRDs' that included questions relative to barriers in modifying fishing gear and reporting bycatch, and, lastly, (6) standard socio-demographic questions. The semi-structured interview consisted of both simple (i.e. questions requiring relatively easy and factual responses) and in-depth open-ended questions (e.g. questions that required more thoughtful, subjective, and descriptive responses) and was designed to be completed in $30 \mathrm{~min}$.

\section{Sampling methods}

In collaboration with the Ontario Commercial Fisheries Association (OCFA), we obtained names and phone numbers of individuals who own one or more commercial fishing licenses for live capture gear in eastern Ontario. Fishers who had not fished within the last 5 yr were excluded as we were interested in current perspectives. A pre-test of the interview questions was conducted with 2 researchers familiar with the Ontario live capture commercial fishery. Questions were then refined. The OCFA provided a list of 88 commercial fishing licenses in eastern Ontario which authorized the use of fyke nets. From this, we identified 58 commercial fishers (some individuals owned multiple licenses). Fourteen individuals were inactive fishers (i.e. owned a license but no longer fished for various reasons), resulting in a sample frame of 44 potential respondents. Note that 2 of the inactive fishers were given a partial interview at their request.

One interviewer conducted all telephone surveys. An introductory letter about the study was sent, $1 \mathrm{wk}$ prior to initial contact by the interviewer, to each license-holder by the OCFA who recommended participation in the study and provided a brief overview of methods and the process. The OCFA board of directors reviewed the objectives of the study and the general approach, but had no input on, or prior knowledge of, the actual study questions. The initial contact letter from the OCFA essentially provided verification that the interviewers were a trusted independent source. An initial contact was made to schedule an interview time and to answer any questions or concerns. Voice- 
mails were left on the third or fourth phone call, and, after a fifth phone call with no answer or no call backs, we stopped attempts to schedule an interview with the individual. Each interview had a preface with a statement explaining the purpose, benefits, and risks of the study and to assure fishers that the interview data were confidential and responses would be anonymized. If an interview was scheduled and the participant was not available or did not answer, the interviewer tried 3 more times at various times until the individual was reached or phoned back; otherwise it was deemed a no response.

\section{Analysis}

Interview notes and audio recordings were imported into qualitative data analysis software (NVivo 9). The interviews were transcribed as needed (for more in-depth questions and notes that were incomplete or lacked detail). Common themes and patterns in responses were summarized and tallied for each topic/section, and alternative responses were noted (Patton 1990). We use quotations to illustrate common themes or alternative responses, and wherever possible we indicate the number of respondents (in percentage) who gave similar responses.

\section{RESULTS AND DISCUSSION}

To the best of our knowledge, our study is the first to evaluate freshwater commercial fishers' perspectives and attitudes regarding turtle bycatch issues and potential solutions. Of the 44 individuals, 18 completed the full telephone interview, and one was given a partial interview because of communication challenges. Nine individuals never responded, and 6 fishers' contact information was no longer valid and they could not be located. Additionally, 5 individuals refused to participate, and 5 had scheduled an interview but did not respond during the scheduled time and follow-up phone calls. As a result, we received responses from $41 \%$ of active commercial fishers in the eastern Ontario commercial fishery population. Although the absolute number of respondents was low, we believe it is representative of active fishers in the eastern Ontario commercial fishery due to the relatively good ( $41 \%$ ) response rate of the entire sample frame. However, we may not have captured the perspectives of fishers with significant distrust or animosity towards fisheries management who declined the interview. Indeed, the work was funded by the
Species at Risk Research Fund of the OMNR, and we declared that to the participants in the initial contact letter. Even though interviewed fishers agreed to respond to our questions, there was still some skepticism and concerns about negative consequences of the research towards their fishing opportunities - a common view also shared by marine fishers (Hall et al. 2007, Carruthers \& Neis 2011). These concerns are important as they emphasize the need for fisheries management and authorities, as well as research scientists, to maintain transparency and to involve stakeholders in decision-making processes (Cowx \& Gerdeaux 2004, Kaplan \& McCay 2004). The involvement of the fishers is especially timely because recent scientific research on turtle bycatch in the region has led fishers to be concerned about the implications the findings may have for their fishing opportunities.

\section{Fishery context: socio-demographics and livelihood}

Participants in this study were all male, with an average age of 54, ranging from 39 to $70 \mathrm{yr}$ old. Five out of 18 fishers described fishing as their sole source of income, whereas the rest have other occupations (e.g. tourism business, hunting lodge manager, and farming). Five respondents (28\%) have post-secondary education, 8 completed high school (44\%), and 5 respondents $(28 \%)$ have some high school education.

Here, we illustrate the personal value of the fishery to the livelihoods, both financially and culturally, of the commercial fishers to provide context. We asked respondents to rank on a scale of 1 to 5 (1 being lowest in importance and 5 being highest) the importance of fishing as part of their income. Seven of the $18(39 \%)$ respondents selected '5', 3 (17\%) selected '4', $6(33 \%)$ selected '3', and 2 (11\%) respondents selected '2'. However, a larger number of respondents rated commercial fishing of higher importance to their lifestyle rather than income: 10 of 17 participants (59\%) selected '5', 5 (29\%) people selected ' 4 ', and $2(12 \%)$ selected ' 3 '. Two respondents described the importance of the fishery as:

It [the fishery] is very much important to me. It's my family history. Our houses, buildings, and life are designed around it.

It's a heritage situation because my dad had it basically forever. I mean his grandfather was a fisherman, and his grandfather was a fisherman. So it's like 100 years of fishing. Plus, it's good income. It's not just a hobby, it's a job.

Four types of answers were given when respondents were asked about their perspective on the fish- 
ery and its personal importance. There were individuals that valued the fishery as very important to their livelihoods. In many cases, the fishery serves as part of personal heritage and has been a part of their families for up to 5 generations. For some respondents, commercial fishing is a hobby and they do it for the love of it. On the other hand, some described the fishery as a business, while other fishers were not as hopeful and described it as a 'dying fishery'.

Many fishers have raised the issue that there are too many restrictions, regulations, and environmental disruptions (i.e. invasive species, pollution) that have devastated the fishery, making it difficult to make a living out of it.

I won't let them [children] get into fishing - no way. I don't want them to go through what I went throughthere's no future. The quota is not enough to make a living out of fishing.

We illustrate the significance of the fishery to the livelihoods of these commercial fishers to provide better a context for fishers' perspectives and attitudes related to turtle bycatch and conservation. The fishers' concern for having a tenable long-term fishery to maintain their income and livelihood makes them ambivalent about adoption of BRSs - a perception also shared among fishers worldwide (e.g. Piovano et al. 2012). Any additional changes, restrictions and costs to the 'dying' fishery would raise opposition to proposed changes. An individual whose income and life are highly dependent on the fishery will suffer from more restrictions and regulations associated with bycatch reduction strategies, where such changes can be viewed as a threat to their way of life (reviewed by Carawan 2004). Similarly, highly committed recreational fishers, who are dependent on the resource of interest, show greater reluctance than less committed recreational fishers in adopting restrictive regulations or changes (e.g. Salz \& Loomis 2005, Dorow et al. 2010, Dorow \& Arlinghaus 2012). Clearly, this longestablished fishery has significant personal value and importance to the participants. This value along with beliefs, social structure, and world views will play an inherent role in a fisher's perspective on, and attitude towards, turtle bycatch and conservation initiatives and what they perceive as an ecological risk (Stern 2000, Slimak \& Dietz 2006).

\section{Fishing practices and turtle encounters}

The interviewed commercial fishers have an average of $39 \mathrm{yr}$ of fishing experience, ranging between $\sim 20$ and 70 yr. All but 2 respondents became in- volved with the fishery through family; the other 2 started it as a business. The number of fyke nets that each fisher set varied from 3 to 70 . The habitats in which the nets were set were mostly 'bays and marshy areas', with the odd fisherman setting in open water. Most fishers preferred setting the leads along the shorelines. The depth of the net sets varied among fishers, from $0.6 \mathrm{~m}$ up to about $26.0 \mathrm{~m}$; however, the most frequently reported depths were between 0.9 and $3.0 \mathrm{~m}$. All fishers fished in the spring only, or spring and fall; only 1 respondent fished solely in the fall. The preferred target species in this fishery are yellow perch and sunfish. All respondents but one (i.e. the sole respondent fishing in open water) indicated catching turtles as bycatch.

The turtle encounters reported by respondents were dependent on several factors: time of year (fishing season), temperature, weather, surrounding habitat, and depth of the set. In addition, we noted that fishers in different zones/geographic locations had different experiences with turtle encounters. A number of fishers described turtles being caught only if nets were set in shallow waters, near marshes, and at times of the year when the water was warm (midlate May and into June), with rare encounters in the fall during cooler temperatures:

Most of the time when you catch a turtle, $90 \%$ it's in shallow water. When you go [into] deep water, it's in the fall and the turtles are already headed into the mud. I hardly catch any in the fall. For the 3.5 months I may catch 10 maybe, whereas in you know, April, May, and June, I can catch 100 a day.

Clearly, there is diversity in fishing styles and behaviour (i.e. depth of net sets, habitat, preferred target species, number of nets) of each individual, which can influence turtle encounters. Turtle encounters were found to be an important factor in acceptance of bycatch reduction devices among fishers in the United States shrimp trawl fishery. Gulf of Mexico shrimpers, who infrequently captured sea turtles ( 1 turtle per $322 \mathrm{~h}$ fished), outright rejected turtle excluder devices (TEDs), as opposed to South Atlantic shrimpers, who caught turtles more frequently (1 turtle per $20 \mathrm{~h}$ fished) and showed more support for TEDS (reviewed in Tucker et al. 1997). The frequency of turtle captures and encounters may play an important role in shaping an individual's perception and acceptance of the link between fisheries and potential turtle population declines.

Traditional knowledge of fishers provides useful information that may otherwise be difficult to obtain (Neis et al. 1999, Haggan et al. 2007, Carruthers \& 
Neis 2011). For instance, the fishers' observations of turtle encounters could provide fisheries-dependent monitoring for population estimations and distributions (specifically for highly aquatic and cryptic species such as musk turtles). However, fishers may be dishonest about reporting bycatch for fear of negative repercussions, as suggested by some participants. The interviewees had a good understanding of the time of year in which turtles are most commonly encountered (e.g. spring/summer) and that the potential for mortality increased with warmer temperatures, as indicated in the scientific literature (Fratto et al. 2008, Larocque et al. 2012a). Fishers also identified that different depths and habitats had different rates of turtle encounters, which may allow for the identification of turtle 'hot spots'. Fisher knowledge (e.g. timing of events, locations) of these turtle 'hot spots' may help managers, scientists, and fishers work collaboratively to reduce bycatch mortalities (e.g. by gear modification or avoiding hot spots) while increasing fishing opportunities in regions with low turtle encounters. Referred to as 'cooperative fisheries research' by Johnson \& van Densen (2007), the integration of scientists' research-based knowledge and fishers' experienced-based knowledge to conduct scientific research can promote 'buy-in' to science-based management and provide fishers with a better understanding of science, as well as an opportunity to communicate their knowledge to scientists (Jenkins 2007, Johnson \& van Densen 2007, Johnson 2011). Cooperation can also promote adaptive and customized solutions, such as different modifications for different fishing scenarios (i.e. deep water was less of a concern; shallow water use floats) or for different times of the year. Flexible arrangements in the implementation of new management and conservation strategies, such as allowing fishers to develop their own BRDs to meet conservation objectives, may increase compliance and support for changes, as such an approach includes a strong industry (i.e. commercial fishing) representation (Gullet 2003).

\section{Perspective on turtle conservation}

The majority of participants were not aware of the conservation status of Ontario turtles, nor was it obvious to them why there was interest in turtle conservation. In response to the topic of turtle conservation, 5 fishers declared that they had not observed declines in turtles in the surrounding areas that they fish. For example:
We always caught them (turtles), we used to sell them at one time and even that didn't make much of a difference. We still see the same amount as before - there is no decline.

Four respondents acknowledged the importance and slow reproduction of turtles as meriting conservation efforts. The remainder of the fishers did not know, or provided their personal opinions as to why there is an interest in turtle conservation.

Furthermore, 5 respondents saw no real need for turtle conservation initiatives and questioned the sudden interest in turtles. Such suspicion may reflect the perception and awareness of fishers concerning turtle endangerment (see subsequent subsections). A couple of respondents strongly believed that the push for turtle conservation is not necessary, that this could be a waste of resources, and that there are greater problems that should be addressed such as habitat loss, invasive species, and the recreational fishing sector. For example:

I think it's another feel good situation, people see something they think they can help that doesn't need helping. I think the population is healthy in my 40 years. There were more snapping turtles back then even when they were fishing for them. I think there are more important things that we could spend some time on.

Four respondents were neutral about turtle conservation, primarily because it had never occurred to them that it was an issue until the interview, and 9 respondents acknowledged that turtles may need help. Interestingly, we noted that the majority of interviewed fishers brought up the fact that they used to be allowed to sell turtles in the past, which could potentially play a role as a psychological barrier to accepting or acknowledging that turtles are a concern, given that they were traditionally allowed to harvest them. This indicates an opportunity in which awareness and education may play an important role in turtle conservation in the eastern Ontario commercial fyke net fishery (see subsequent subsections).

\section{Perceived threats to turtle populations}

Interviewed fishers identified several factors which they perceived as threats to turtle populations, such as habitat loss, pollution and water quality, road kills, raccoons and blue herons eating turtle eggs, and food shortage due to competition with cormorants. Five respondents were not aware there was a threat to turtle populations nor were they aware of what could cause their declines. None identified commer- 
cial fishing as a threat, suggesting a strong perception that any threat is external to the fishery.

\section{Perspectives on turtle bycatch}

All fishers responded that turtle bycatch was not an issue or threat to turtle populations, particularly with a good fisher who regularly checks his nets. This general perception was associated with several beliefs: live-capture methods 'don't hurt turtles' and allow turtles to be live-released; there are substantially decreased numbers of people fishing; commercial fishers use good fishing practices and 'if they see turtles in nets and it's a problem, they will pull the nets out and move them'; commercial fishers are conservation-oriented and are concerned with the welfare of wildlife; and the 'number of turtles being caught is not enough to endanger them'. In response to bycatch being an issue for turtle populations, respondents stated:

Absolutely not, there has always been bycatch, there is always some mortality, and there are still lots of turtles. I don't see it as an issue.

I check my nets often; I keep my nets cleaned out, and also get better fish. Turtles can hold air for quite a long time, and when water is warmer, I try and get there sooner. When it's warm out, you got to get there more often, and your fish spoils quicker too.

Only 1 respondent noted that he sees fewer snapping turtles now. The perception that turtle bycatch and commercial fishing activities are not an issue for turtle conservation and the overall perception that the threats are external to the fishery present significant barriers to fishers adopting BRSs (Stern 2000, Slimak \& Dietz 2006). These perceptions may be largely attributed to the overall lack of awareness about the consequences of adult turtle mortality on the population, i.e. that slight additional adult mortality can lead to population declines (Brooks et al. 1991, Congdon et al. 1993, 1994). Various threats to turtle populations exist, including habitat degradation, pet trade, consumption, and road mortality, which render turtles some of the most endangered vertebrates worldwide (Rhodin et al. 2011). The real impact of commercial fishing on freshwater turtle populations is currently unknown, but is potentially important. The true effect of a fishery on turtle populations may not be observable over the span of a career. Several species take nearly $20 \mathrm{yr}$ or more to reach sexual maturity (Congdon et al. 1993), so the compounded effects of removing a few adult females may take decades to become noticeable by observation and even longer for the population to recover.
Education and promoting awareness about turtle biology, the slow maturation process, and the potential impact of just a few adult mortalities on the population may facilitate acceptance turtle conservation initiatives such as BRSs (De Young 1993, Heimlich \& Ardoin 2008). Interviewed fishers are conservation oriented in that they 'don't like to see things hurt or die' and are 'in touch with nature', which suggests that an increase in knowledge and awareness could be beneficial. As such, encouraging voluntary stewardship through education and incentive programs (e.g. Hall 1996, Ferraro \& Gjertsen 2009) is likely to yield positive results, particularly if stakeholders are engaged from start (e.g. planning, design) to finish (e.g. implementation, monitoring; reviewed by Cox et al. 2007).

\section{Perspectives on bycatch mortality}

Interviewed fishers reported turtle mortality as very rare (only 4 respondents reported observing any turtle mortality). All respondents agreed that postcaptured turtles were in good condition and lively. All interviewed fishers were very aware that long net sets can cause turtle mortality. Respondents also noted that mortality was also temperature dependent and can occur when water is warm.

However, when asked about the long-term effects of net captures on turtles, a third of the respondents showed some uncertainty. Two respondents thought that it depended on the length of time the turtle was trapped inside the net and on temperature. The rest of the respondents agreed that turtles do not endure long-term consequences from the capture event, in particular, if the nets are emptied frequently. For example:

Turtles are amazingly tough, one time I had a big turtle stuck in my net, biggest one I saw. I thought he was a goner, but I put him up on the lawn and an hour later he took off.

One fisher associated turtle post-capture behaviour with fish and raised the concept of recovery time. He stated:

You can see delayed mortality with fish that were observed to be sluggish. If an animal showed near drowning and was allowed to revive, they would do absolutely fine. There is no physical damage.

The variation in responses regarding the postrelease fate of captured turtles highlights the need for more research, particularly focussed on assessing potential physiological and behavioural consequences and recovery times, as well as delayed mortality. To 
our knowledge, no information on the post-release fate of freshwater turtles from fishery capture (particularly from anoxia) exists. Information on sub-lethal impacts (e.g. reproductive or feeding impairments) and post-release mortality are essential for population risk assessments and for identifying ways in which to release turtles that minimize stress and maximize survival. Overall, more biological research is required to solidify any existing threat of the fishery to freshwater turtle populations to convince fishers that a 'real' problem exists. Acknowledgement of such a problem is a key first step to engaging fishers in coming up with mitigation strategies.

\section{Bycatch reduction}

We sought to explore strategies that commercial fishers presently use or suggestions they have to avoid catching turtles and to maximize their survival within a net. A couple of fishers did not believe that mortalities from net captures were an issue. Eight of 18 respondents believed that there is 'no way you can prevent turtles coming into your nets' and that 'fishermen are always going to get bycatch, depending on where they fish.'

On the other hand, 4 respondents talked about voluntarily moving nets to avoid turtles. A couple of fishers lift nets regularly throughout the week to avoid long net sets. Four respondents described methods that they have used, or have seen people use, to ensure survival of captured turtles, such as,

leaving an inch at the surface so they can breathe or close the front ends of the net to keep snapping turtles out.

However, a number of respondents stated that muskrats will damage nets that are above the water and that this method is not ideal. Again, this could be an issue in certain geographical areas only. One respondent described that if a turtle was sluggish they left the turtle on the boat to recover until it looked healthy and could go back overboard.

Interestingly, 1 respondent has developed his own gear modification which consists of a floating device (i.e. beach ball) that is:

placed at the tail end of the net (at the very last hoop), and once the net is tied and everything is settled, the ball slowly brings the tail end of the net up about 4-6 inches out of the water.

Thus, turtles have access to air. The respondent continues to describe that turtles are mainly captured at a depth of about $1.5 \mathrm{~m}$ and that this method is most successful at this depth and not in deeper waters. Successful cases of fisher-invented technologies exist to exclude or reduce turtle bycatch. Jenkins (2010) described successfully certified fisher-designed TEDs in the United States shrimp trawl fishery involving shrimpers as inventors and scientists as modifiers of TEDs. Engaging and adopting fisher-invented BRDs can lead to more effectiveness and efficiency by decreasing the time between problem identification and coming up with relevant and practical solutions. Furthermore, fisher inventors were more influential in promoting adoption of their TEDs, and, in 1 case, the adoption of a local invention was 6 -fold higher than the adoption of other devices (reviewed in Jenkins 2010).

\section{Gear modifications: bycatch reduction devices}

Overall, it appeared that interviewed fishers did not want to forfeit fishing opportunities. As such, gear modifications or other alternatives would be preferred over closures. During the interviews we described 2 BRDs that have been previously explored for this fishery (Larocque et al. 2012b); the first was described as:

a device that can help prevent turtles from getting into the nets, such as exclusion bars, which are vertical bars at the front of the net that can prevent turtles from swimming into the net due to their large shells.

The second was described as:

a device that could provide a way for turtles to get air, such as a chimney, which is an extension from the net made of mesh that reaches the surface to allow turtles to get air.

Diagrams of these devices can be found in the publication by Larocque et al. (2012b). We asked respondents for their thoughts on these BRDs and on personally modifying their gear. We received a wide range of responses.

The general attitudes towards the introduced BRDs were negative and skeptical. Respondents highlighted several concerns in terms of costs, catch efficiency, and practicality, while some maintained their position that these devices are not necessary (Table 1). Of the 2 BRDs introduced, the vertical exclusion bars appeared to be more attractive to the interviewed fishers than the escape chimney. Specific concerns with the vertical exclusion bars included exclusion of bigger fish (e.g. common carp Cyprinus carpio) and lower catch efficiency. Interviewed fishers also questioned the efficiency of excluding all species of turtles, while still catching fish. A couple of respondents were concerned with the added weight and the challenges of handling the modified net. However, 9 respondents 
Table 1. Concerns and opinions regarding 2 bycatch reduction devices, vertical exclusion bars and an escape chimney, and general thoughts on gear modifications. Responses are listed in order of most frequently mentioned. Numbers in brackets indicate number of respondents that have raised the concern/opinion. Multiple responses may be recorded for each respondent

\begin{tabular}{|c|c|c|c|}
\hline Vertical exclusion bars & Escape chimney & $\begin{array}{l}\text { Thoughts about gear } \\
\text { modifications }\end{array}$ & Alternative responses \\
\hline $\begin{array}{l}\text { Decrease in catch } \\
\text { efficiency (8) }\end{array}$ & $\begin{array}{l}\text { Impracticality with varying } \\
\text { depths of sets (5) }\end{array}$ & $\begin{array}{l}\text { Not a good idea/not } \\
\text { worth it (7) }\end{array}$ & $\begin{array}{l}\text { Encourage stewardship through } \\
\text { education (i.e. move net if } \\
\text { catching too many turtles) }\end{array}$ \\
\hline $\begin{array}{l}\text { Could work depending } \\
\text { on spacing of bars (4) }\end{array}$ & $\begin{array}{l}\text { Nets can get folded over with } \\
\text { winds and water fluctuations (4) }\end{array}$ & Costs (6) & $\begin{array}{l}\text { Leave } 2 \mathrm{~cm} \text { at the surface for } \\
\text { turtles to breathe }\end{array}$ \\
\hline Exclusion of bigger fish (3) & Create muskrat problems (3) & Would try it (3) & $\begin{array}{l}\text { Insert beach ball to lift tail-end of } \\
\text { net to surface }\end{array}$ \\
\hline $\begin{array}{l}\text { Will not exclude smaller } \\
\text { turtles without excluding } \\
\text { target fish }(2)\end{array}$ & $\begin{array}{l}\text { Potential safety hazards } \\
\text { during lifts and sets, and } \\
\text { for boaters ( } 2 \text { ) }\end{array}$ & Time and effort (2) & \\
\hline $\begin{array}{l}\text { Additional weight and } \\
\text { handling of nets }(2)\end{array}$ & $\begin{array}{l}\text { Turtle jagged shells can get } \\
\text { caught on mesh (2) }\end{array}$ & $\begin{array}{l}\text { It did not decrease } \\
\text { catch efficiency (1) }\end{array}$ & \\
\hline $\begin{array}{l}\text { Weeds can get caught } \\
\text { on bars (1) }\end{array}$ & $\begin{array}{l}\text { Fish can plug up the } \\
\text { chimney (1) }\end{array}$ & $\begin{array}{l}\text { Will modify gear if it } \\
\text { is mandatory }(2)\end{array}$ & \\
\hline $\begin{array}{l}\text { Animals can get wedged } \\
\text { between bars (1) }\end{array}$ & $\begin{array}{l}\text { Chimney between the first } \\
2 \text { funnels would be } \\
\text { optimum (1) }\end{array}$ & $\begin{array}{l}\text { Need compensation } \\
\text { or subsidies }(3)\end{array}$ & \\
\hline Use stiff rope as bars (1) & & & \\
\hline
\end{tabular}

indicated that vertical exclusion bars had potential, but were not fully convinced:

Might work but who will pay to get us to do that. It's bad enough that we have to pay for all our other stuff.

If it worked I'd be up for it, as long as it doesn't affect fishing too much and add too much work.

The escape chimney was negatively received, primarily because of perceived impracticality:

It sounds like a pain in the butt. I can see fish getting into it, and what if it's all folded over. The water fluctuation might come up, and the chimney may not reach the top. And if you make it too long, you'll have meshy things all over the place, floating around and you need floats and stuff on it, just sounds impractical.

One prominent reason for the impracticality of the escape chimney was the issue of varying depths of net sets. Other concerns included the escape chimney at the surface being a safety hazard to recreational users on the water, as well as attracting muskrats that would subsequently chew holes in the nets (Table 1).

\section{Barriers to acceptance of bycatch reduction devices}

Interviewed fishers provided several opinions on the topic of personal gear modifications. Ten respondents believed that gear modifications were not necessary:
I personally don't think it's that big of a deal, for the number of turtles that we get and are killed, to me it's a small percentage, and I believe that probably doing this would cause more problems down the road that is unforeseen.

A couple of respondents would only modify their gear if it were made mandatory. A number of fishers would potentially modify their gear as long as it did not affect their catch, was not too much work, and did not cost them money. This is a common hurdle for fisheries management to overcome as marine fishers have voiced similar opinions when presented with different BRDs or gear substitutions (Tucker et al. 1997, Broadhurst 2000, Jenkins \& Garrison 2013). In the case of the eastern Ontario commercial fishery, target fish catch reductions have not occurred when BRDs were experimentally implemented (Larocque et al. 2012b); providing this information to fishers may make them more amenable to using such devices. Benefits from using BRDs, such as processing efficiency, quicker sorting time, reduced damage to nets caused by larger turtles, and potential to have longer set durations may also give fishers a more positive outlook on BRDs (e.g. Brewer et al. 1998). Addressing the specific concerns of the fishers, who intimately know their fishing gear, will not only facilitate the acceptance of BRSs, but could improve proposed designs and encourage fishers to be part of the solution (e.g. voluntary stewardship/actions). This 
approach of 'unforced innovation' proved to be successful in the Australian shrimp trawl industry, where fishers were given the opportunity to work with government agencies to develop BRDs, and were allowed the flexibility to perform trials, modify, and improve devices to suit their needs (Tucker et al. 1997).

Additionally, some respondents also showed an attitude of 'What's in it for me?' and would expect some compensation or subsidies (Table 1):

I'm game as long as it doesn't cost money out of my own pocket to do it. I have a family of 7 . I have 61 nets and it's going to cost pretty penny to have them turtles saved. So unless they subsidize me or something it would be a no.

If someone wanted to put bars on the nets of my design, at someone else's expense and time, and showed to me that they are as capable as catching the same amount of fish than my design, then fine. I am not prepared to go through time and expenses of doing that, and knowing how awkward it would be to set a net like that with that kind of attachment in water depths that I traditionally set. I refuse to put in time or money to experiment with that sort of thing, especially if I'm not going to be issued extra nets to my license.

One respondent described that he modified his own gear to increase net efficiency and to adapt to environmental changes caused by zebra mussels (i.e. increased water clarity), and noted that gear modifications to reduce turtle bycatch would be counterproductive to his efforts to increase the efficiency of his nets. Again, this reinforces that fishers ultimately know their own gear and how to maximize its efficiency; therefore, they are the best go-to sources when designing and developing BRSs.

Regulatory approaches to BRDs have failed due to resistance and non-compliance in the marine realm (e.g. Moberg \& Dyer 1994, Hall \& Mainprize 2005, Gilman et al. 2006a), particularly if the innovation is perceived as an economic burden and the regulatory changes conflict with existing perceptions (Rogers \& Shoemaker 1971, Moberg \& Dyer 1994). An incentive system could prove to be favorable over regulatory approaches: rewarding fishers who contribute least to the problem and penalizing those who fail or are less motivated to mitigate their impacts (Hall 1996, Ferraro \& Gjertsen 2009). An incentive system may also promote development of new bycatch reduction techniques, by providing greater economic advantage to those who initiate responsible fishing and also weeding out poor performers, thus raising the standard for all fishers involved. Incentive-based approaches could vary in terms of economic rewards or advantages (e.g. subsidies, lower taxes, and other monetary rewards), or fishing opportunities such as longer fishing seasons or higher allocated quotas for fishers who do not exceed an established bycatch limit, perform at an established standard (e.g. regular net checks, setting nets that leave air pockets, adopting BRDs), or initiate development of mitigation strategies and/or technologies (for more examples see Hall 1996).

\section{Bycatch reporting}

Lastly, in the interview we asked respondents about potentially reporting bycatch and received a range of responses. Eight fishers did not mind it, 4 respondents regarded it as more paperwork, and 4 others showed distrust and believed this concept was a 'double-edged sword'. For example:

If I start to report lots of turtles, then I get a knock on the door saying I can't fish anymore. I'd be real careful about what I report. It can come back and bite me in the ass.

A couple of fishers would do it if it was mandatory, and 1 fisher believed reporting bycatch was unproductive and could be misleading:

In an ideal world I have no problems with it, but because of how certain facts or numbers can be interpreted, I would be reluctant because it doesn't tell the condition or context of it.

Similarly to the adoption of BRDs, bycatch reporting is likely to be successful and accurate if fishers are made aware of its objectives and importance in turtle conservation and understand that reporting does not present a threat to their fishing opportunities and way of life, and if it is adopted as voluntary stewardship rather than enforced. Information from bycatch reports can be critical to maintaining viable turtle populations and sustainable fisheries.

\section{CONCLUSIONS}

Introducing freshwater turtle bycatch reduction strategies such as BRDs in fisheries management of the eastern Ontario commercial fyke net fishery involves many considerations. Our research identified a number of potential barriers to the adoption of BRSs, ranging from psychometric to socio-economic variables. Here, we highlight the need to consider the importance of the fishery to the livelihoods of the fishers, as any negatively perceived change presents a barrier to adopting any BRS. The frequency of turtle encounters and captures can also influence a fisher's perception and awareness of turtle endanger- 
ment and the necessity for conservation action. The lack of awareness and outreach among fishers with respect to turtle conservation status, turtle life-history traits, the post-release fate of captured turtles, and other characteristics that raise conservation concerns may lead to apprehension about turtle conservation initiatives, as well as presenting a significant barrier to accepting the potential impact of the fishery on turtle populations. Finally, the costs and burden associated with using BRDs were a predominant factor influencing fisher support for the implementation of such devices.

How can fisheries management address and overcome the barriers that exist between commercial fishers and the adoption of BRSs? It is evident from the literature and from our own research that fisher engagement and contribution, along with expertise from scientists, are required for successful development and implementation of BRSs, and to maintain sustainable fisheries (e.g. Hall et al. 2007, Jenkins 2007, 2010, Piovano et al. 2012). As such, we argue that adopting 'co-management' — an arrangement in which responsibilities for the management of resources are shared among government, user groups, and other stakeholders through cooperative processes (Jentoft et al. 1998) — as well as 'cooperative fisheries research' (Johnson \& van Densen 2007), would help ensure long-term viability of the fisheries while meeting conservation objectives. Furthermore, simply promoting awareness and providing education on turtle biology and the importance of turtle conservation could foster voluntary stewardship and conservation initiatives among commercial fishers (as already initiated in this fishery). Voluntary stewardship may be a better alternative than regulatory approaches (Cooke et al. 2012), and applying an incentive-based system may help facilitate and promote these conservation-oriented actions. By engaging user groups and co-managing the fishery, fishers would be motivated and empowered to develop, implement, and self-monitor mitigation measures in order to maintain a viable and sustainable fishery.

Acknowledgements. We thank Kevin Reid from the Ontario Commercial Fisheries Association for providing us with access to their members, and Mary F. Hanley for her assistance in providing historical background on the fishery. We are grateful to the fishers that participated in the survey and to Dr. Nathan Young for his input. Funding was provided by the Species at Risk Research Fund for Ontario through the OMNR. Additional support was provided by the Canadian Wildlife Federation and the Canada Research Chairs Program. Ethics approval was obtained from the Carleton University Ethics Committee in accordance with provincial and federal privacy legislation.

\section{LITERATURE CITED}

Barko VA, Briggler JT, Osendorf DE (2004) Passive fishing techniques: a cause of turtle mortality in the Mississippi River. J Wildl Manag 68:1145-1150

Bishop JM (1983) Incidental capture of diamondback terrapin by crab pots. Estuaries Coasts 6:426-430

- Brewer D, Rawlinson N, Eayrs S, Burridge C (1998) An assessment of bycatch reduction devices in a tropical Australian prawn trawl fishery. Fish Res 36:195-215

$>$ Broadhurst MK (2000) Modifications to reduce bycatch in prawn trawls: a review and framework for development. Rev Fish Biol Fish 10:27-60

Brooks RJ, Brown GP, Galbraith DA (1991) Effects of sudden increase in natural mortality of adults on a population of the common snapping turtle (Chelydra serpentine). Can J Zool 69:1314-1320

Campbell LM, Cornwell ML (2008) Human dimensions of bycatch reduction technology: current assumptions and directions for future research. Endang Species Res 5: 325-334

Carawan LW (2004) Added layers of stress in the commercial fisheries. Stress Trauma Crisis Int J 7:187-207

Carrière MA (2007) Movement patterns and habitat selection of common map turtles (Graptemys geographica) in St. Lawrence Islands National Park, Ontario, Canada. MSc dissertation, University of Ottawa, Ottawa

Carruthers EH, Neis B (2011) Bycatch mitigation in context: using qualitative interview data to improve assessment and mitigation in a data-rich fishery. Biol Conserv 144: 2289-2299

Congdon HD, Dunham AE, van Loben Sels RC (1993) Delayed sexual maturity and demographics of Blanding's turtles (Emydoidea blandingi): implications for conservation and management of long-lived organisms. Conserv Biol 7:826-833

Congdon JD, Dunham AE, van Loben Sels RC (1994) Demographics of common snapping turtles (Chelydra serpentina): implications for conservation and management of long-lived organisms. Integr Comp Biol 34:397-408

Cooke SJ, Suski CD, Arlinghaus R, Danylchuk AJ (2012) Voluntary institutions and behaviours as alternatives to formal regulations in recreational fisheries management. Fish Fish, doi:10.1111/j.1467-2979.2012.00477.x

COSEWIC (Committee on the Status of Endangered Wildlife in Canada) (2013) Wildlife species search: database of wildlife species assessed by COSEWIC. www.cosewic. gc.ca/eng/sct1/searchform_e.cfm. (accessed 11 February 2013)

Cowx IG, Gerdeaux D (2004) The effects of fisheries management practices on freshwater ecosystems. Fish Manag Ecol 11:145-152

> Cox TM, Lewison RL, Zyclelis R, Crowder LB, Safina C, Read AJ (2007) Comparing effectiveness of experimental and implemented bycatch reduction measures: the ideal and the real. Conserv Biol 21:1155-1164

De Young R (1993) Changing behaviour and making it stick: the conceptualization and management of conservation behaviour. Environ Behav 25:485-505

Ditton RB (2004) Human dimensions of fisheries. In: Manfredo MJ, Vaske JJ, Bruyere BL, Field DR, Brown PJ (eds) Society and natural resources: a summary of knowledge prepared for the 10th internal symposium on society and resource management. Modern Litho, Jefferson, MO, p 199-208

> Dorow M, Arlinghaus R (2012) The relationship between personal commitment to angling and the opinions and attitudes of German anglers towards the conservation 
and management of European eel Anguilla anguilla. N Am J Fish Manag 32:466-479

Dorow M, Beardmore B, Haider W, Arlinghaus R (2010) Winners and losers of conservation policies for European eel, Anguilla anguilla: an economic welfare analysis for differently specialised eel anglers. Fish Manag Ecol 17: 106-125

Ferraro PJ, Gjertsen H (2009) A global review of incentive payments for sea turtle conservation. Chelonian Conserv Biol 8:48-56

Fratto ZW, Barko VA, Pitts PR, Sheriff SL and others (2008) Evaluation of turtle exclusion and escapement devices for hoop-nets. J Wildl Manag 72:1628-1633

Gilman E, Zollett E, Beverly S, Nakano H and others (2006a) Reducing sea turtle bycatch in pelagic longline fisheries. Fish Fish 7:2-23

Gilman E, Dalzell P, Martin S (2006b) Fleet communication to abate fisheries bycatch. Mar Policy 30:360-366

Gullet W (2003) Enforcing bycatch reduction in trawl fisheries: legislating for the use of turtle exclusion devices. Environ Planning Law J 20:195-210

Haggan N, Neis B, Baird IG (2007) Fisher's knowledge in fisheries science and management. Coastal Management Sourcebooks, UNESCO Publications, Paris

Hall MA (1996) On bycatches. Rev Fish Biol Fish 6:319-352

Hall MA, Mainprize BM (2005) Managing by-catch and discards: How much progress are we making and how can we do better? Fish Fish 6:134-155

Hall MA, Nakano H, Clarke S, Thomas S and others (2007) Working with fishers to reduce bycatches. In: Kennelly $\mathrm{SJ}$ (eds) Bycatch reduction in the world's fisheries. Springer-Verlag, New York, NY, p 235-285

- Heimlich JE, Ardoin NM (2008) Understanding behaviour to understand behaviour change: a literature review. Environ Educ Res 14:215-237

Hubert WA (1996) Passive capture techniques. In: Murphy BR, Willis DW (eds) Fisheries techniques, 2nd edn. American Fisheries Society, Bethesda, MD, p 157-192

> Jenkins LD (2007) Bycatch: interactional expertise, dolphins and the U.S. tuna fishery. Stud Hist Philos Sci 38:698-712

Jenkins LD (2010) Profile and influence of the successful fisher-inventor of marine conservation technology. Conserv Soc 8:44-54

Jenkins LD, Garrison K (2013) Fishing gear substitution to reduce bycatch and habitat impacts: an example of social-ecological research to inform policy. Mar Policy 38:293-303

Jentoft S, McCay BJ, Wilson DC (1998) Social theory and fisheries management. Mar Policy 22:423-436

> Johnson TR (2011) Fishermen, scientists, and boundary spanners: cooperative research in the U.S. Illex squid fishery. Soc Nat Resour 24:242-255

> Johnson TR, van Densen WLT (2007) Benefits and organization of cooperative research for fisheries management. ICES J Mar Sci 64:834-840

Kaplan IM, McCay BJ (2004) Cooperative research, co-management and the social dimension of fisheries science and management. Mar Policy 28:257-258

Kennelly SJ (1999) The development and introduction of bycatch reducing technologies in three Australian prawn-trawl fisheries. Mar Technol Soc J 33:73-81

Kennelly SJ, Broadhurst MK (1996) Fishermen and scientists solving bycatch problems: examples from Australia and possibilities for the northeastern United States. In: Alaska Sea Grant College Program (eds) Solving bycatch: considerations for today and tomorrow. Alaska Sea Grant College Program Report No. 96-03, University of Alaska, Fairbanks, AK, p 121-128

> Larocque SM, Colotelo AH, Cooke SJ, Blouin-Demers G, Haxton T, Smokorowski KE (2012a) Seasonal patterns in bycatch composition and mortality associated with a freshwater hoop net fishery. Anim Conserv 15:53-60

> Larocque SM, Cooke SJ, Blouin-Demers G (2012b) Mitigating bycatch of freshwater turtles in passively-fished hoop nets through the use of exclusion and escape modifications. Fish Res 125-126:149-155

> Larocque SM, Cooke SJ, Blouin-Demers G (2012c) A breath of fresh air: avoiding anoxia and mortality of freshwater turtles in fyke nets by the use of floats. Aquat Conserv 22:198-205

Lewison RL, Crowder LB, Read AJ, Freeman SA (2004) Understanding impacts of fisheries bycatch on marine megafauna. Trends Ecol Evol 19:598-604

Lewison RL, Soykan CU, Cox T, Peckham H and others (2011) Ingredients for addressing the challenges of fisheries bycatch. Bull Mar Sci 87:235-250

Lowry MB, Pease BC, Graham K, Walford TR (2005) Reducing the mortality of freshwater turtles in commercial fish traps. Aquat Conserv 15:7-21

Mascia MB, Brosius JP, Dobson TA, Forbes BC, Horowitz L, McKean MA, Turner NJ (2003) Conservation and the social sciences. Conserv Biol 17:649-650

Moberg M, Dyer CL (1994) Conservation and forced innovation: response to turtle excluder devices among Gulf of Mexico shrimpers. Hum Organ 53:160-166

Moore JE, Cox TM, Lewison RL, Read AJ and others (2010) An interview-based approach to assess marine mammal and sea turtle captures in artisanal fisheries. Biol Conserv 143:795-805

Neis B, Schneider DC, Felt L, Haedrich RL, Fischer J, Hutchings JA (1999) Fisheries assessment: What can be learned from interviewing resource users? Can J Fish Aquat Sci 56:1949-1963

Patton MQ (1990) Qualitative evaluation and research methods. SAGE Publications, London

> Piovano S, Basciano G, Swimmer Y, Giacoma C (2012) Evaluation of a bycatch reduction technology by fishermen: a case from Sicily. Mar Policy 36:272-277

Raby GD, Colotelo AH, Blouin-Demers G, Cooke SJ (2011) Freshwater commercial bycatch: an understated conservation problem. BioScience 61:271-280

Rhodin AGJ, Walde AD, Horne BD, van Dijk PP, Blanck T, Hudson R (2011) Turtles in trouble: the world's 25+ most endangered tortoises and freshwater turtles-2011. IUCN/SSC Tortoise and Freshwater Turtle Specialist Group, Lunenburg, MA

Rogers EM, Shoemaker FF (1971) Communication of innovations: a cross-cultural approach. The Free Press, New York, NY

> Salz RJ, Loomis DK (2005) Recreation specialization and anglers' attitudes towards restricted fishing areas. Hum Dimens Wildl 10:187-199

Slimak MW, Dietz T (2006) Personal values, beliefs, and ecological risk perception. Risk Anal 26:1689-1705

Stern PC (2000) Toward a coherent theory of environmentally significant behaviour. J Soc Issues 56:407-424

Tucker AD, Robins JB, McPhee DP (1997) Adopting turtle excluder devices in Australia and the United States: What are the differences in technology transfer, promotion, and acceptance? Coast Manag 25:405-421

Watson J (2007) Reconciling fisheries with conservation through programs to develop improved fishing technologies in the United States. In: Kennelly SJ (eds) Bycatch reduction in the world's fisheries. Springer, Dordrecht, p 23-36 